\title{
Immunohistochemical localization of inhibin and activin subunits, activin receptors, and Smads in ovarian clear cell adenocarcinoma
}

\author{
YASUSHI MABUCHI, MAREO YAMOTO, SAWAKO MINAMI and NAOHIKO UMESAKI \\ Department of Obstetrics and Gynecology, Wakayama Medical University, \\ School of Medicine, 811-1 Kimiidera, Wakayama 641-0012, Japan
}

Received August 25, 2005; Accepted October 24, 2005

\begin{abstract}
Our purpose was to examine the immunolocalization of inhibin, activin and the activin signaling system in ovarian clear cell adenocarcinoma tissue. Tissue samples of ovarian clear cell adenocarcinoma were collected from ten women. The patients' ages ranged from 41 to 71 years (mean \pm standard deviation; 53.4 \pm 9.9 ). Their surgicopathological staging was based on the criteria of the International Federation of Gynecology and Obstetrics (FIGO); there were 5 patients with stage I, 3 with stage II, and 2 with stage III. We examined the immunohistochemical localization of inhibin/ activin $\alpha$-subunit, $B \mathrm{~A}$-subunit, activin $\mathrm{A}$, and activin receptor types IA, IB, IIA, IIB, Smad2, Smad3 and Smad4 using an avidin-biotin-peroxidase complex technique. With the antibodies against the BA-subunit, and activin $\mathrm{A}$, we observed positive immunoreactive staining in the cytoplasm of clear cell adenocarcinoma, whereas we did not observe any staining for the $\alpha$-subunit of inhibin. We observed positive immunoreactive staining in the cell cytoplasm and surface with the antibodies against the activin receptors, types IA, IB, IIA and IIB. We observed positive immunoreactive staining in the cytoplasm and nucleus with the antibodies against the $\operatorname{Smad} 2, \operatorname{Smad} 3$ and Smad4. It is suggested that activin A, not inhibins, might be secreted by ovarian clear cell adenocarcinoma, and that an activin signal transduction pathway might exist in ovarian clear cell adenocarcinoma.
\end{abstract}

\section{Introduction}

Ovarian cancer is the leading cause of death due to gynecological malignancy, even though the diagnostic methods or treatment techniques for cancer have progressed markedly.

Correspondence to: Dr Yasushi Mabuchi, Department of Obstetrics and Gynecology, Wakayama Medical University, School of Medicine, 811-1 Kimiidera, Wakayama 641-0012, Japan

E-mail: booyan@wakayama-med.ac.jp

Key words: ovarian cancer, clear cell adenocarcinoma, activin, inhibin, activin receptor, Smad
Ovarian cancer has especial factors which are influential in the poor prognosis of ovarian cancer, such as difficulty of early detection and resistance to chemotherapy. Clear cell adenocarcinoma of the ovary is one of the tumors with the poorest prognosis of all the histological types of ovarian cancer. Clinically, several characteristics distinguish clear cell adenocarcinoma from other histological types of epithelial ovarian carcinoma, including a high frequency of associated endometriosis, resistance to platinum-based chemotherapy and poor prognosis even in the early stages of disease.

Activins and inhibins belong to the transforming growth factors- $\beta$ superfamily (1) and are involved in the regulation of cell growth and differentiation in various kinds of tissue $(2,3)$. Activins and inhibins are dimeric glycoproteins which are isolated from ovarian follicular fluid. Activins are composed of two homologous $B$-subunits, and three forms, activin $A$ $(\beta \mathrm{A} / \mathrm{BA})$, activin $\mathrm{B}(\mathrm{B} / \mathrm{BB})$, and activin $\mathrm{AB}(\mathrm{BA} / \mathrm{BB})$, have been identified. Inhibins consist of an $\alpha$-subunit that is linked to a $\beta$-subunit by disulfides, and two forms, inhibin $\mathrm{A}(\alpha / \beta \mathrm{A})$ and inhibin $B(\alpha / \beta B)$, have been characterized (4). Activins stimulate the secretion of follicle-stimulating hormone (FSH) from anterior pituitary gland, whereas inhibins inhibit FSH secretion.

Activin and TGF- $\beta$ ligands bind to ligand-specific receptors, yet the actions of both growth factors are mediated through the same cytoplasmic signaling components, Smads (5-8). Activin initially binds to an activin type II receptor (ActR IIA or ActR IIB) with high affinity and specificity. Following the binding, the complex recruits a second (type I) receptor (ActR IA or ActR IB) to form an activin type I-II receptor complex. This union promotes phosphorylation at serine or threonine of type I receptors, which results in the phosphorylation of two possible receptor-regulated cytoplasmic coactivators (R-Smad 2 and R-Smad 3) which then interact with the common Smad (co-Smad 4) (9-12). The phosphorylated and activated Smad 2/4 or Smad 3/4 complex translocates to the cell nucleus where they play a prominent role in the transcription of activin or TGF- $\beta$ responsive genes (11). Inhibitory Smads (I-Smad 6 and I-Smad 7) block the phosphorylation of R-Smads by preventing their association with the type I receptor in the cell cytoplasm, which results in the inhibition of additional Smad signaling $(11,13)$.

The signaling pathway of inhibin is less clearly understood. There are neither specific receptor isolated nor specific 
threonine/serine kinases identified from genomic searches (14). Recently, Lewis et al (15) reported that the association of inhibin with an accessory binding protein (betaglycan, so called TGF- $\beta$ receptor type III) promoted inhibin binding to ActR II and that the association was a very potent antagonist of activin binding and action.

We previously reported that sex cord stromal tumors might produce inhibin A and inhibin B (16). Concerning epithelial tumors, we reported that inhibin and activin might be secreted by mucinous adenoma and cystic tumors with borderline malignancy and that activins might be secreted by mucinous adenocarcinoma and serous tumors including benign adenoma, cystic tumors with borderline malignancy, and adenocarcinoma (17). However, there are no detailed data concerning the expression of inhibin and activin subunits, activin receptors and Smad proteins in ovarian clear cell adenocarcinoma. In the present study, we examined the immunohistochemical localization of inhibin $\alpha-, \beta A$-subunit, activin A, activin receptors, and Smad proteins in ovarian clear cell adenocarcinoma.

\section{Materials and methods}

Materials. Tissue samples of ovarian clear cell adenocarcinoma were obtained from ten women who were admitted to Wakayama Medical University Hospital from 1997 to 2003. The patients' ages ranged from 41 to 71 years (mean \pm standard deviation; 53.4 \pm 9.9 ). Their surgicopathological staging was based on the criteria of the International Federation of Gynecology and Obstetrics (FIGO); there were 5 patients with stage I, 3 with stage II, and 2 with stage III.

The project was approved by the committee on investigations involving human subjects of Wakayama Medical University, School of Medicine. Informed consent was obtained from each patient after the purpose and nature of the study had been fully explained.

Immunohistochemistry. Antibodies against inhibin/activin $\alpha$ and BA-subunits were purchased from Serotec (Oxford, UK). Monoclonal antibodies were directed against synthetic peptides that correspond to amino acids 1-32 of the $\alpha$-subunit and 82114 of the BA-subunit of $32-\mathrm{kDa}$ inhibin A. The monoclonal antibody against activin A was prepared as described previously (18). Mouse monoclonal antibodies against activin receptor types IA and IIB and goat polyclonal antibodies against activin receptor types IB and IIA were purchased from R\&D Systems (Minneapolis, MN). The antibodies against activin receptor types IA, IB, IIA and IIB were directed against the recombinant human activin receptor types IA, IB, IIA and IIB extracellular domain. Goat polyclonal antibodies against Smad2, Smad3 and the mouse monoclonal antibody against Smad4 were purchased from Santa Cruz Biotechnology (Santa Cruz, CA). The monoclonal antibody against Smad4 was directed against peptides that correspond to amino acids 1-552 representing full-length Smad4 of human origin. The goat polyclonal antibodies against Smad2 and Smad3 were directed against peptides mapping within the amino terminal domain of Smad2 and Smad3 domain of human origin.

The ovarian tissue samples were fixed in formalin, embedded in paraffin and cut into $5-\mu \mathrm{m}$ sections. Immuno- histochemical procedure was performed via the avidin-biotinperoxidase complex technique using a Vectastain $\mathrm{ABC}$ kit (Vector Laboratories, Burlingame, CA). Briefly, the tissue sections were deparaffinized, rehydrated in a graded ethanol series, and washed with $0.05 \mathrm{~mol} / 1$ phosphate buffer, $\mathrm{pH} 7.4$. The sections were incubated for 30 min with $3 \% \mathrm{H}_{2} \mathrm{O}_{2}$ in phosphate buffer to quench endogenous peroxidase activity and washed 3 times for 5 min each in phosphate buffer that contained 0.3\% Triton X-100 (Sigma Chemical Co., St. Louis, MO). The sections were incubated for $30 \mathrm{~min}$ at room temperature with $20 \%$ normal horse serum for inhibin $\alpha$ - and BA-subunits, activin receptor types IA, IIB and Smad4, normal goat serum for activin $\mathrm{A}$, or normal rabbit serum for activin receptor types IB, IIA, Smad2 and Smad3 to block non-specific binding. The tissue sections were incubated with primary antibody for $1 \mathrm{~h}$ at room temperature, followed by $16 \mathrm{~h}$ at $4^{\circ} \mathrm{C}$. Each primary antibody was used for analysis at a final concentration of $1 \mu \mathrm{g} / \mathrm{ml}$ ( $\alpha$-subunit, activin A), $2 \mu \mathrm{g} / \mathrm{ml}$ (BAsubunit), $10 \mu \mathrm{g} / \mathrm{ml}$ (activin receptor IB), $20 \mu \mathrm{g} / \mathrm{ml}$ (activin receptors IA, IIA, IIB, Smad3, Smad4), and $5 \mu \mathrm{g} / \mathrm{ml}(\operatorname{Smad} 2)$. The tissue sections were washed with $0.05 \mathrm{~mol} / \mathrm{l}$ phosphate buffer and incubated with biotinylated horse antibodies against mouse $\operatorname{IgG}$ for $\alpha^{-}, \beta$ A-subunits, activin receptor types IA, IIB and Smad4, with biotinylated goat antibodies against mouse IgM for activin A or with biotinylated rabbit antibodies against goat IgG for activin receptor types IB, IIA, Smad2 and Smad3 for $30 \mathrm{~min}$ at room temperature. Antigen-antibody complexes were visualized with diaminobenzidine as the chromogen after incubation with avidin-biotin-peroxidase complex for $30 \mathrm{~min}$ at room temperature. The sections were counterstained with Meyer's hematoxylin and observed under a light microscope.

For preparation of negative controls, samples were treated with preimmune serum of mouse, rabbit, and goat instead of the primary antibodies at the same dilution, and no immunoreactivity was observed.

\section{Results}

Fig. 1 shows the immunolocalization of the inhibin/activin $\alpha-, \beta A-s u b u n i t$, and activin $\mathrm{A}$ in the tissue of ovarian clear cell adenocarcinoma. We did not observe any staining for the $\alpha$-subunit of inhibin (Fig. 1A) in clear cell adenocarcinoma. However, with the antibodies against the BA-subunit (Fig. 1B) and activin A (Fig. 1C), we observed strong immunoreactive staining in the cytoplasm in all cases of clear cell adenocarcinoma. For positive controls, we stained corpora lutea using antibodies against $\alpha$ - and BA-subunit and we observed strong immunostaining for $\alpha$-subunit (Fig. 1D) and BA-subunit (data not shown) in corpora lutea. No immunostaining was observed in ovarian clear cell adenocarcinoma tissue treated with secondary antimouse IgM only (Fig. 1E).

Fig. 2 shows the immunolocalization of the activin receptors, type IA (Fig. 2A), type IB (Fig. 2B), type IIA (Fig. 2C) and type IIB (Fig. 2D) in the tissue of ovarian clear cell adenocarcinoma. In the clear cell adenocarcinoma, we observed positive immunoreactive staining in the cell cytoplasm and surface with the antibodies against the activin receptor, type IA in all cases (Fig. 2A), type IB in 9 of 10 cases (Fig. 2B), type IIA in all cases (Fig. 2C) and type IIB in 4 of 10 cases (Fig. 2D). 

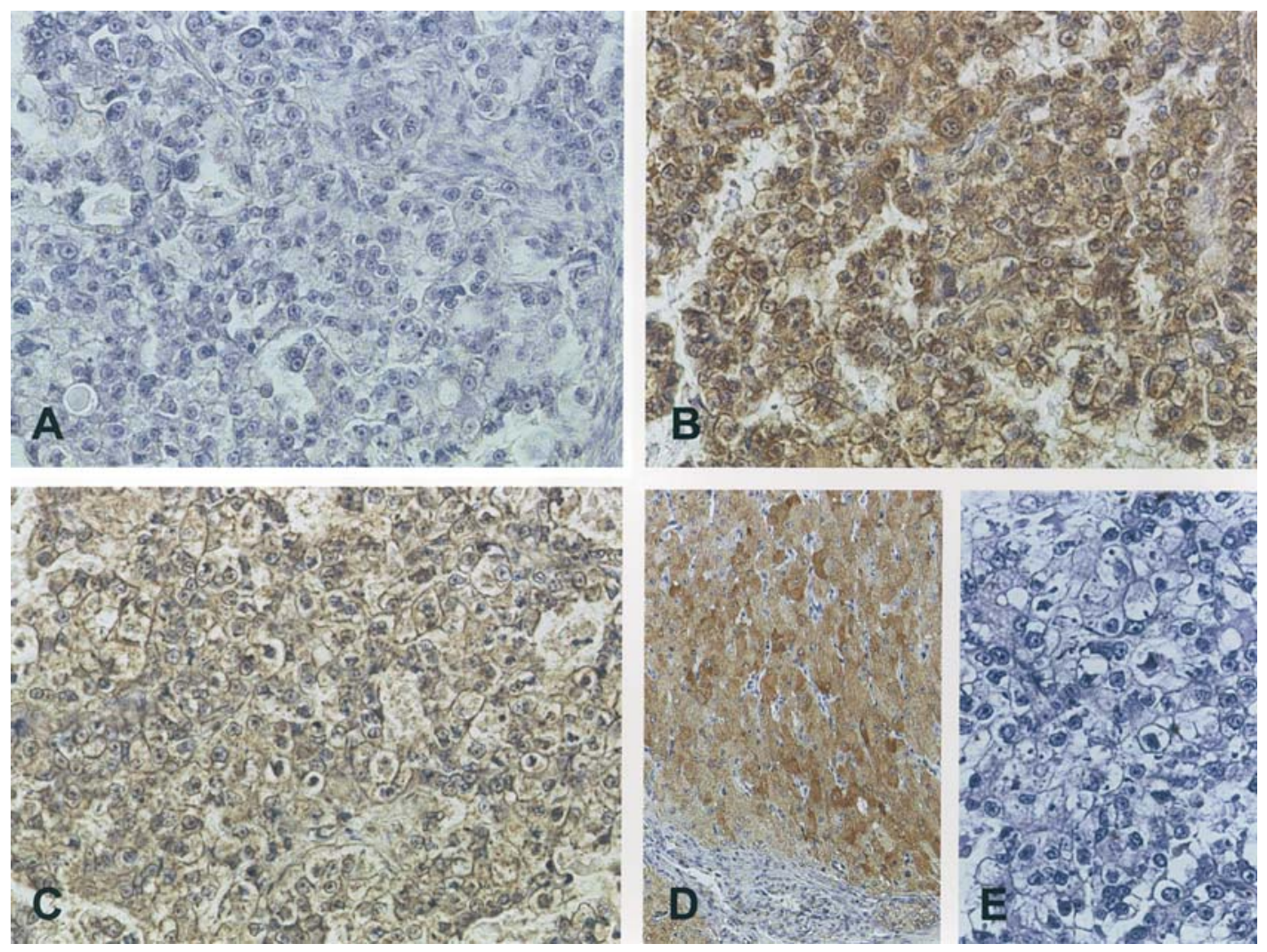

Figure 1. Immunohistochemical localization of $\alpha$-subunit (A), BA-subunit (B) and activin A (C) in human clear cell adenocarcinoma of the ovary. No immunostaining specific for $\alpha$-subunit (A) was observed in ovarian clear cell adenocarcinomas. Staining for BA-subunit (B) and activin A (C) was evident in the cytoplasm of tumor cells. The positive immunostaining for $\alpha$-subunit was observed in luteal cells of the human corpus luteum (D). No immunostaining was observed in ovarian clear cell adenocarcinoma tissue treated with secondary anti-mouse IgM only (E). Original magnification, x200.
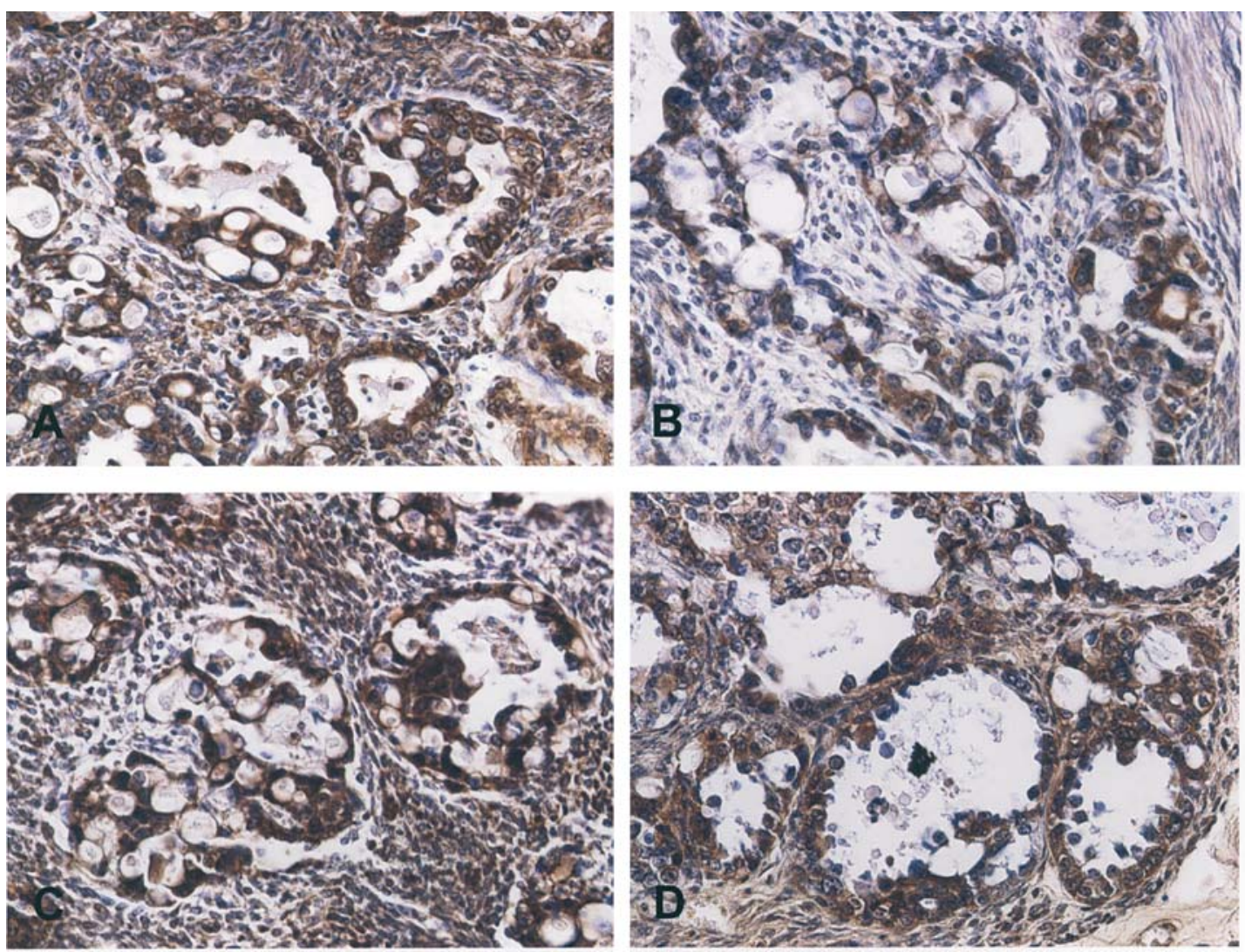

Figure 2. Immunohistochemical localization of activin receptor type IA (A), type IB (B), type IIA (C), and type IIB (D) in human clear cell adenocarcinoma of the ovary. Staining for activin receptors type IA (A), type IB (B), type IIA (C) and type IIB (D) was evident in the cytoplasm and surface of tumor cells. Original magnification, x200. 

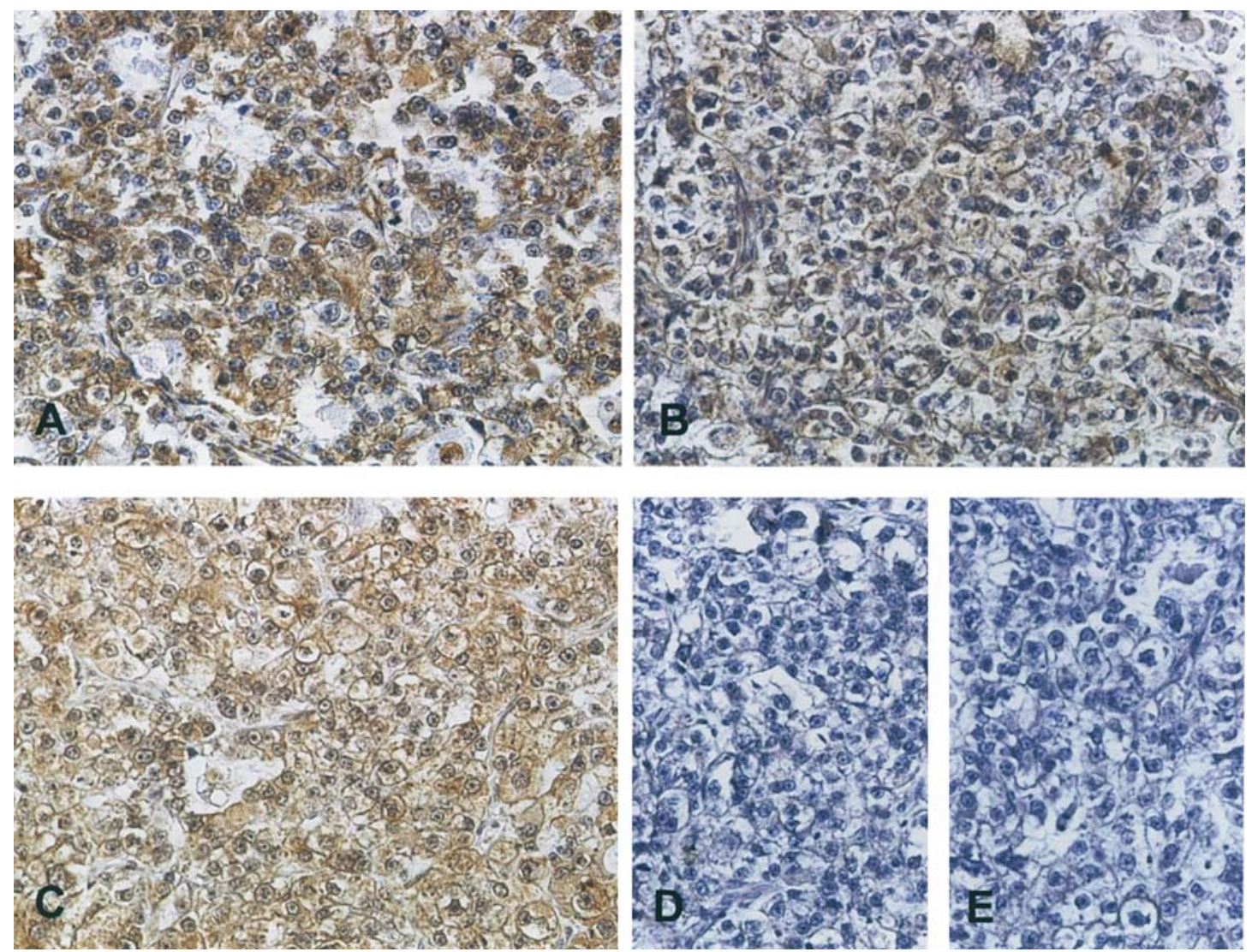

Figure 3. Immunohistochemical localization of Smad2 (A), Smad3 (B), and Smad4 (C) in human clear cell adenocarcinoma of the ovary. Staining for Smad2 (A), Smad3 (B), and Smad4 (C) was evident in the cytoplasm and nucleus of tumor cells. No immunostaining was observed in ovarian clear cell adenocarcinoma tissue treated with secondary anti-goat IgG only (D) and with secondary anti-mouse IgG only (E). Original magnification, x200.

Fig. 3 shows the immunolocalization of the Smad2 (Fig. 3A), Smad3 (Fig. 3B), and Smad4 (Fig. 3C) proteins in the tissue of ovarian clear cell adenocarcinoma. In clear cell adenocarcinoma, we observed strong immunoreactive staining in the cytoplasm and nucleus with the antibodies against Smad2 in 4 of 10 cases (Fig. 3A), Smad3 in 6 of 10 cases (Fig. 3B) and Smad4 in 9 of 10 cases (Fig. 3C). No immunostaining was observed in ovarian clear cell adenocarcinoma tissue treated with secondary anti-goat IgG only (Fig. 3D) and with secondary anti-mouse IgG only (Fig. 3E).

\section{Discussion}

Ovarian clear cell adenocarcinoma has several characteristics distinguishing it from other forms of epithelial ovarian cancer. The percentage of patients with stage I is significantly higher in patients with clear cell adenocarcinoma than in those with serous adenocarcinoma (19). However, clear cell adenocarcinoma has a poorer prognosis than serous carcinoma (20), and the response rate to platinum-based chemotherapy in patients with clear cell adenocarcinoma is significantly lower than that in patients with serous adenocarcinoma (19). Clear cell adenocarcinoma has a lower incidence of p53 mutation than endometrioid adenocarcinoma (21). The doubling time for clear cell adenocarcinoma cells is significantly longer than that for serous adenocarcinoma cells (22). Furthermore, immunohistochemical analyses revealed that clear cell adenocarcinoma had trends of weak expression of both $\mathrm{p} 53$ and cyclin A, and markedly increased expression of both p21 and cyclin E compared with other pathohistological subtypes (23).

The present study demonstrated that immunostaining with antibodies against the BA-subunit and activin A was observed intracytoplasmically in the tumor cells of clear cell adenocarcinoma. We did not detect any staining of $\alpha$-subunit in clear cell adenocarcinoma cells. The stroma, on the other hand, showed faint immunostaining for BA-subunit and activin A. These findings suggest that activin A, but not inhibins, may be produced in the tumor cells of ovarian clear cell adenocarcinoma. Matzuk et al (24) demonstrated that inhibin could act as a novel secreted tumor suppressor protein with specificity for gonadal sex cord stromal tumors by their inhibin deficiency animal study. In addition, Shikone et al (25) demonstrated that activin A could act as an autocrine growth factor that stimulates the proliferation of cell lines derived from the gonadal stromal tumors of inhibin $\alpha$-subunit knockout mice. In humans, we previously reported that sex cord stromal tumors might produce inhibin A and inhibin B (16). Recently, we reported that inhibin/activin subunits were localized in human ovarian serous and mucinous tumors and that overproduction of activins promoted cell proliferation in ovarian serous and mucinous adenocarcinomas (17). Activin A was secreted in cultured human epithelial ovarian cancer (26) and induced cell proliferation in human ovarian cancer cell lines (27). 
In the current study, we demonstrated that immunostaining with antibodies against the activin receptor types IA, IB, IIA and IIB was observed in the cytoplasm and surface of clear cell adenocarcinoma. We also showed immunohistochemical localization of Smad2, Smad3 and Smad4 in the cytoplasm and nucleus of tumor cells. These findings suggest that ovarian clear cell adenocarcinoma may be the target of activin's autocrine/paracrine effects and that the activin signal transduction system is functioning in ovarian clear cell adenocarcinoma. Ito et al (28), using cultured ovarian cancer cell lines, reported that ovarian adenocarcinoma cells expressed mRNA of activin receptor types IA, IIA, IIB, Smad2 and Smad4. Fuller et al (29) reported the mRNA expression of activin receptor types IA, IB, IIA, IIB in mucinous and serous cystadenocarcinoma. They also demonstrated that activin receptor types IA, IB and IIA exhibited wide-spread albeit variable expression across tissues with the highest levels in serous tumor, whereas activin receptor type IIB expression was relatively low in the mucinous tumors (20). In addition, Dunfield et al (30) detected the expression of mRNAs of Smad2, Smad3 and Smad4 in ovarian epithelial cancer cell lines.

Recent literature suggest that Smad proteins suppress cell proliferation in tumors of various tissues. Smad4 gene alteration, which leads to tumor progression, is most prevalent in pancreatic cancer $(31,32)$, whereas it is less frequently observed in ovarian cancer (33). Although mutations in the Smad2 gene have been detected in colorectal cancer (34), their frequency was far less than that of Smad4. Jeruss et al (35) reported that there were significant correlations in breast cancer specimens between a decrease in nuclear Smad3 abundance and high tumor grade, high architecture grade, large tumor size, and hormone receptor negativity.

Recently, Steller et al (36) reported that ovarian cancer cells expressed activin $B A, B B$-subunit, activin receptor types IA, IB, IIA, IIB, Smad2, Smad3 and Smad4 by RT-PCR and Western blotting and that activin A increased cell proliferation whereas inhibin A decreased it in the presence of betaglycan using cultured ovarian cancer cell lines which include clear cell adenocarcinoma. They also showed that nude miceinjected ovarian cancer cells which were not responsive to inhibin's suppressive effects on proliferation had a shorter length of survival time than mice-injected cells responsive to inhibin and suggested that inhibin resistance might contribute to the aggressiveness of ovarian cancer cells. The present study demonstrated immunostaining for activin signaling components and the translocation of Smad proteins into the nuclei in ovarian clear cell adenocarcinoma. In addition to these findings, activin signaling components might be involved in the genesis and the advance of ovarian clear cell adenocarcinoma.

In conclusion, we observed strong immunoreactive staining with antibodies against BA-subunit and activin $\mathrm{A}$ in ovarian clear cell adenocarcinoma. It is suggested that activin A, not inhibins, may be produced by clear cell adenocarcinoma. We also demonstrated the immunolocalization of activin receptor types IA, IB, IIA, IIB, Smad2, Smad3 and Smad4 in ovarian clear cell adenocarcinoma, which suggested that the activin signal transduction system might exist in ovarian clear cell adenocarcinoma. It is possible that activin may have autocrine roles in the tumorigenesis of ovarian clear cell adenocarcinoma.

\section{Acknowledgements}

We thank Dr Y. Eto (Central Research Laboratories, Ajinomoto Co., Inc., Kawasaki, Japan) for donating the monoclonal antibody against recombinant human activin $\mathrm{A}$.

\section{References}

1. Massague J: Transforming growth factor beta family. Annu Rev Cell Biol 6: 597-641, 1990.

2. Mason AJ, Hayflick JS, Ling N, et al: Complementary DNA sequences of ovarian follicular fluid inhibin show precursor structure and homology with transforming growth factor- $\beta$. Nature 318: 659-663, 1985.

3. Lapolt PS and Hsueh AJW: Molecular basis of inhibin production and action. Mol Cell Neurosci 2: 449-463, 1991.

4. Vale W, Rivier C, Hsueh AJW, et al: Chemical and biological characterization of the inhibin family of protein hormones. Recent Prog Horm Res 44: 1-34, 1988.

5. Nakao A, Imamura T, Souchelnytskyi S, et al: TGF- $\beta$ receptormediated signaling through Smad2, Smad3, and Smad4. EMBO J 16: 5353-5362, 1997.

6. Whitman M: Smads and early developmental signaling by the TGF- $\beta$ superfamily. Genes Dev 12: 2445-2462, 1998.

7. Yue J and Mulder KM: Requirement of RAS/MAPK pathway activation by transforming growth factor- $\beta 1$ production in a Smad-dependent pathway. J Biol Chem 275: 30765-30773, 2000.

8. Yue $\mathrm{J}$ and Mulder KM: Transforming growth factor- $\beta$ signal transduction in epithelial cells. Pharmacol Ther 91: 1-34, 2001.

9. Woodruff TK and Mather JP: Inhibin, activin and the female reproductive axis. Annu Rev Physiol 57: 219-244, 1995.

10. Risbridger GP, Schmitt JF and Robertson DM: Activin and inhibins in endocrine and other tumors. Endocr Rev 22: 836-858, 2001.

11. Attisano L and Tuen Lee-Hoeflich S: The Smads. Genome Biol 2: 3010.1-3010.8, 2001

12. Shi Y, Hata A, Lo RS, Massague J and Pavletich NP: A structural basis for mutational inactivation of the tumour suppressor Smad4. Nature 388: 87-93, 1997.

13. Massague J: TGF- $ß$ signal transduction. Annu Rev Biochem 67: 753-791, 1998.

14. Pangas SA and Woodruff TK: Activin signal transduction pathways. Trends Endocrinol Metab 11: 309-314, 2000.

15. Lewis KA, Gray PC, Blount AL, et al: Betaglycan binds inhibin and can mediate functional antagonism of activin signaling. Nature 404: 411-414, 2000.

16. Yamashita K, Yamoto M, Shikone T, et al: Production of inhibin A and inhibin B in human ovarian sex cord stromal tumors. Am J Obstet Gynecol 177: 1450-1457, 1997.

17. Yamashita K, Yamoto M, Shikone T, Minami S and Nakano R: Immunohistochemical localization of inhibin and activin subunits in human epithelial ovarian tumors. Am J Obstet Gynecol 180: 316-322, 1999.

18. Otani T, Minami S, Kokawa K, Shikone T, Yamoto M and Nakano R: Immunohistochemical localization of activin A in human endometrial tissues during the menstrual cycle and in early pregnancy. Obstet Gynecol 91: 685-692, 1998.

19. Sugiyama T, Kamura T, Kigawa J, et al: Clinical characteristics of clear cell carcinoma of the ovary: distinct histologic type with poor prognosis and resistance to platinum-based chemotherapy. Cancer 88: 2584-2589, 2000.

20. Tammela J, Geisler JP, Eskew PN and Geisler HE: Clear cell carcinoma of the ovary: poor prognosis compared to serous carcinoma. Eur J Gynaecol Oncol 19: 438-440, 1998.

21. Okuda T, Otsuka J, Sekizawa A, et al: p53 mutation and overexpression affect prognosis of ovarian endometrioid cancer but not clear cell cancer. Gynecol Oncol 88: 318-325, 2003.

22. Itamochi H, Kigawa J, Akeshima R, et al: Mechanisms of cisplatin resistance in clear cell carcinoma of the ovary. Oncology 62: 349-353, 2002.

23. Shimizu M, Nikaido T, Toki T, Shiozawa T and Fujii S: Clear cell carcinoma has an expression pattern of cycle regulatory molecules that is unique among ovarian adenocarcinomas. Cancer 85: 669-677, 1999.

24. Matzuk MM, Finegold MJ, Su JG, Hsueh AJ and Bradley A: Alpha-inhibin is a tumour-suppressor gene with gonadal specificity in mice. Nature 360: 313-319, 1992. 
25. Shikone T, Matzuk M, Perlas E, et al: Characterization of gonadal sex cord-stromal tumor cell lines from inhibin-alpha and $\mathrm{p}-53$ deficient mice: the role of activin as an autocrine growth factor. Mol Endocrinol 8: 983-985, 1994.

26. Welt CK, Lambert-Messerlian G, Zheng W, Crowley WF and Schneyer AL: Presence of activin, inhibin, and follistatin in epithelial ovarian carcinoma. J Clin Endocrinol Metab 82: 3720-3727, 1997.

27. Di Simone N, Crowley WF, Wang QF, Sluss PM and Schneyer AL: Characterization of inhibin/activin subunit, follistatin, and activin type II receptors in human ovarian cancer cell lines: a potential role in autocrine growth regulation. Endocrinology 137: 486-494, 1996.

28. Ito I, Minegishi T, Fukuda J, Shinozaki H, Auersperg N and Leung PCK: Presence of activin signal transduction in normal ovarian cells and epithelial ovarian carcinoma. Br J Cancer 82: 1415-1420, 2000

29. Fuller PJ, Zumpe ET, Chu S, Mamers P and Burger HG: Inhibinactivin receptor subunit gene expression in ovarian tumors. J Clin Endocrinol Metab 87: 1395-1401, 2002.

30. Dunfield LD, Dwyer EJC and Nachtigal MW: TGF- $\beta$ induced Smad signaling remains intact in primary human ovarian cancer cells. Endocrinology 143: 1174-1181, 2002.
31. Miyaki M and Kuroki T: Role of Smad4(DPC4) inactivation in human cancer. Biochem Biophys Res Commun 306: 799-804, 2003.

32. Hahn SA, Schutte M, Hoque ATMS, et al: DPC4, a candidate tumor suppressor gene at human chromosome 18q21.1. Science 271: 350-353, 1996

33. Schutte M, Hruban RH, Hedrick L, et al: DPC4 gene in various tumor types. Cancer Res 56: 2527-2530, 1996.

34. Eppert K, Scherer SW, Ozcelik H, et al: MADR2 maps to 18q21 and encodes a TGF- $\beta$ regulated MAD-related protein that is functionally mutated in colorectal carcinoma. Cell 86: 543-552, 1996.

35. Jeruss JS, Sturgis CD, Rademaker AW and Woodruff TK: Downregulation of activin, activin receptors, and Smads in high-grade breast cancer. Cancer Res 63: 3783-3790, 2003.

36. Steller MD, Shaw TJ, Vanderhyden BC and Ethier JF: Inhibin resistance is associated with aggressive tumorigenicity of ovarian cancer cells. Mol Cancer Res 3: 50-61, 2005. 